\title{
The Way \\ Free, fee, or subsidy? The future role of libraries
} I See It

\author{
By William L. Whitson
}

\section{Libraries' mainstay: Providing access, gateways, and assistance}

$\mathbf{L}$ ibraries today must adapt to a combination of changes so unprecedented and fundamental that our very future is in question. Survival depends on identifying our unique role: what we do that no one else can or will. I believe that the unique role of libraries has always been an economic one: what I call "providing subsidized access to shared resources."

\section{Diminishing roles for libraries}

What about collecting and storing information resources? Isn't that our main role? In fact, many other organizations, agencies, and individuals, both public and private, collect and store information, and with the digital and telecommunications revolution, what others have is becoming increasingly available. In the evolving electronic environment, it is no longer necessary or economically practical for us to continue to give this role nearly as much importance as we have in the past. As a "node" on the Internet - which will begin to function as world library-the individual library will simply be one information supplier among many.

What about organizing information for retrieval? While we may have had a significant role in the development of library cataloging standards and practices, most indexing and bibliographic control of even library materials has always been done by others in the scholarly and publishing worlds. In spite of the efforts some in the research library community are making to shape retrieval mechanisms in the electronic environment, most of these developments are being driven by forces in the computer and commercial spheres, and too quickly for us to keep up with, let alone dominate. We can influence aspects of the evolving retrieval structures, but this will also be a relatively marginal role for libraries.

What about library instruction? While those using information resources may have more need for instruction than ever before, and academic libraries in particular may still play a part in providing systematic instruction, there is little evidence that many information users look to libraries for such instruction. More important, however, the network revolution has thrown the doors wide open and vastly extended the population of people with some expertise in information seeking. Most of the instruction taking place in the future will probably occur through other channels (even if it's being done by librarians freelancing).

None of these traditional concepts affords us a unique role that will ensure our survival.

\section{The unique role of libraries}

What libraries always bave done, and no one else will do, is provide a particular client or "user" constituency with access to shared resources at a cost below what they would have to pay on their own: in other words, subsidized access to shared resources.

The concept of shared resources is fundamental. The library's constituency has shared interests and finds it cheaper to pool funds and share resources than to require each individual to acquire everything he or she needs. In theory, anyone with enough money could purchase access to all he or she needed. In fact, many business enterprises do this routinely. Even in the scholarly community, most faculty members probably get most of their information through purchase or other nonlibrary channels, and changes in the electronic networked environment and in the publishing world will make 
them even less dependent on their local library Most of those in the academic community, however, cannot afford to purchase everything they need individually. They rely on libraries to acquire or provide access to it. Libraries, however, will still have to "select" which resources their particular clienteles most need to access.

\section{"Free and fee"}

You will notice that I do not say "free access." Most of us accept as a cardinal rule the stricture that we should always provide access to scholarly resources "free of charge." At most, fees might be levied for "luxury services" such as document delivery. I believe the time has come for us to begin to provide "differentiated access" - some resources free, others for a fee.

How can we possibly justify charging our primary clientele fees for basic library materials and services? First, we should acknowledge that access to resources through the library has never been entirely "free." We have always "charged" in what we require of the user in terms of time, effort, investment in learning access protocols (research methods!), and in terms of compliance with bureaucratic procedures. (Indeed, one might argue plausibly that, much of the time, many of our constituents already find our "prices" too high. They choose either to get their information some other way or to do without.) Certainly, for some faculty, it is much "cheaper" to pay a few dollars for an article delivered in the mailbox than to spend the time and effort necessary to find the article in the library and photocopy it.

More important, however, is the fact that we can no longer afford to make all relevant resources available to our faculty and students free. I think most of us would agree it is preferable to make some resources available for a fee which covers at least part of the cost (and deters unnecessary use) than not to make those resources available at all. If we are to remain relevant today, we must become the "cheaper gateway" through which our constituencies can have access to whatever information resources they need.

As transactions take place increasingly through electronic channels, we can easily build in authentication and accounting mechanisms which will allow us to charge users partial fees. The negotiation of licensing agreements with commercial information vendors will have to include provisions for differentiated access. For example, with a periodical article supplier, a particular library or consortium may arrange to pay one level of subsidy for undergraduate students for a certain set of periodical titles, and a lesser subsidy for other titles, and a still different subsidy for other groups such as faculty or graduate students or alumni library cardholders. Transactions would take place as simply as now, but the charge presented to the individual requestor would depend on the person's status determined by the authentication process. The library "selection" process would thus be extended to include not only which resources should be provided, but what level of fee (if any) would be assessed for each clientele group.

\section{Contributions of the new library}

What, then, will be our role? Our unique "valueadded" contributions will be in three areas:

1) Access: providing our own constituents with access to the resources they need, and subsidizing the costs of access to the extent necessary to make the use of those resources practical. This would include traditional purchase and ownership, but increasingly will mean leasing electronic access. Providing the computer hardware, software, and telecommunications facilities necessary for effective utilization of such resources will also be a critical library role. For some time to come, a significant fraction of our clients will not have the equipment which would enable them to use the electronic resources most efficiently.

2) Gateway: presenting the resources available through the library "gateway" in the most user-friendly manner. This applies to the way we describe and publicize our services, the layout of the library, signage, etc., and to the design of OPAC, CD-ROM network, gopher, and other interfaces. Increasingly, we will design integrated "client" gateway software, which guides the client to the most relevant resources.

3) Research assistance: assisting clients in finding and using information resources. People will always need help, no matter how welldesigned the gateway. The intellectual problems of defining one's information need, relating it to the increasingly large and complex network of world information resources, and searching those resources efficiently, require more higher-order thinking than ever before. We must ensure that we continue to have at least some staff knowledgeable enough to provide this kind of intellectual assistance, and structure access to that assistance so as to ration it to those who really need it. 